\title{
Survey on synergism effect of ketotifen in combination with pyrimethamine in treatment of acute murine toxoplasmosis
}

\author{
Mahbobeh Montazeri ${ }^{1,2}$, Kian Rezaei ${ }^{1}$, Mohammad Ali Ebrahimzadeh ${ }^{3}$, Mehdi Sharif ${ }^{1,4}$, Shahabeddin Sarvi ,4, \\ Ehsan Ahmadpour ${ }^{5}$, Mohammad Taghi Rahimi ${ }^{6}$, Abdol Satar Pagheh ${ }^{1,2}$, Saeed Mehrzadi and Ahmad Daryani ${ }^{1,4^{*}}$
}

\begin{abstract}
Background: Standard treatment of toxoplasmosis is accompanied by severe side effects and low tolerability; accordingly, alternative medicines are critically needed. Ketotifen (KET) as a cell membrane stabilizer could be an appropriate inhibitor of Toxoplasma gondii (T. gondii) parasite entrance into the host cells. Therefore, the focus of current study is characterization of the anti-Toxoplasma activity of KET in the acute phase of toxoplasmosis in murine model as pre-treatment and post-treatment (before and after infection with RH strain). KET was used intraperitoneally both individually ( 2 and $3 \mathrm{mg} / \mathrm{kg} /$ day) and in combination with pyrimethamine (PYR) (50 mg/ $\mathrm{kg} /$ day). One week after the post infection, DNA was extracted from brain biopsies samples. Parasite load was calculated using Quantitative-PCR (Q-PCR) in a triplicate reaction for each DNA with the target for at RE (a 529 bp repeat element) gene.
\end{abstract}

Results: A significant difference between KET and control groups was observed $(P<0.001)$ in the pre-treatment and post-treatment groups. Both KET and the combination of KET and PYR showed a reduction in the parasite load in brain through the acute phase of the infection. $2 \mathrm{mg} / \mathrm{kg} /$ day dose of KET resulted in higher anti-Toxoplasma activity (15,698 parasites $/ \mathrm{ml}$ ) compared to $3 \mathrm{mg} / \mathrm{kg} /$ day dose of KET $(72,898$ parasites $/ \mathrm{ml})$ in brain in the pre-treatment group. In addition, KET combined with PYR significantly decreased the parasite load in the post-treatment group.

Conclusions: Our results indicated that KET has both prophylactic and therapeutic effects on acute phases of the disease.

Keywords: Toxoplasma gondii, Ketotifen, Cell membrane stabilizer, Quantitative PCR

\section{Background}

Toxoplasma gondii (T. gondii), a ubiquitous intracellular parasite, is the etiologic agent of toxoplasmosis [1]. Approximately, over 1 billion of the world population is chronically infected by $T$. gondii. This infection can be transmitted to humans by various transmission pathways [2].

Toxoplasma infection is usually considered self-limiting. However, it is important due to the danger of reactivation of latent infection which sometimes can be fatal in immunocompromised hosts. Furthermore, acquiring the infection during pregnancy via congenital route, particularly

\footnotetext{
*Correspondence: daryanii@yahoo.com

'Toxoplasmosis Research Center, Mazandaran University of Medical Sciences, Sari, Iran

${ }^{4}$ Department of Parasitology and Mycology, Sari Medical School, Mazandaran University of Medical Sciences, Sari, Iran

Full list of author information is available at the end of the article
}

in the first trimester, can cause either major congenital malformations or spontaneous abortion among pregnant women who have no efficient immunity to $T$. gondii or previous exposure [3-5]. The available medications for treatment of toxoplasmosis are a combination of pyrimethamine and sulfadiazine, but the efficacy of the current therapies is limited in some cases, particularly due to significant toxicity or development of drug-resistances in parasites [6]. Additionally, the available therapies have no effect against tissue cystic stage or bradyzoites of the parasite [7, 8]. In recent years, researchers have concentrated on finding more efficacious and less toxic parasite-specific drugs against toxoplasmosis [6].

Apical end of $T$. gondii tachyzoite plays a major role during invasion and attachment process of the parasite to host cell. Moreover, some surface antigens such as 
perforin-like proteins assist the interaction between the tachyzoite and the host cell. This vital procedure for the parasite is accompanied by sequential secretion of three morphologically and functionally distinct organelles including micronemes, rhoptries, and dense granules. Dysfunction of any part of this essential process would be expected either to kill or inhibit the parasite invasion $[9,10]$.

Ketotifen (KET), a tricyclic benzocycloheptathiophene derivate, is broadly used in the control of some ailments such as allergy, asthma, and inflammatory disorders. It blocks $\mathrm{H} 1$ receptors, stabilizes mast cells, and inhibits eosinophil accumulation and degranulation that results in the further stabilization of the cell membrane $[11,12]$.

It was also shown that KET, propranolol, and cromolyn sodium act as cell membrane stabilizer drugs, and thus can inhibit penetration of $T$. gondii tachyzoite into nucleotide cells [13-15]. In continuation of our previous studies, KET was evaluated, for anti-Toxoplasma activity on acute phase of toxoplasmosis in a murine animal model.

\section{Methods}

\section{Parasites}

Tachyzoites of the highly virulent $\mathrm{RH}$ strain of $T$. gondii were used for experiments which routinely obtained by serial intraperitoneal (IP) passages in Balb/c female mice in Toxoplasmosis Research Center, Mazandaran University of Medical Sciences, Sari, Iran [7, 16].

\section{Mice}

In the current study, all the experiments were conducted on female Balb/c mice weighing 18-20 g (6-week-old). All mice were housed in cages $(n=4)$ under standard laboratory conditions including an average temperature 20-25 ${ }^{\circ} \mathrm{C}$, given drinking water, and regular diet [17].

\section{Experimental design and groups}

All drugs were purchased from Sigma-Aldrich. This survey was done in pre-treatment and post-treatment groups on $48 \mathrm{Balb} / \mathrm{c}$ mice in 12 subgroups $(n=4)$ through the acute-phase of infection as previously described [7]. Briefly, in the pre-treatment study, KET both individually (2 and $3 \mathrm{mg} / \mathrm{kg} /$ day) and also in combination with PYR (50 mg/kg/day) (as the positive control) and PBS (as the negative control) was injected intraperitoneally 6,12 , and $48 \mathrm{~h}$ before the challenge test. In the post-treatment study, the mice were infected with $1 \times$ $10^{3}$ of RH strain; then were treated 6,12 , and $48 \mathrm{~h}$ with the same drugs. One week after the infection, the brain biopsies of all subgroups were obtained [7].

\section{DNA extraction and detection of $T$. gondii RE gene using Q-PCR}

DNA was extracted from brain biopsies using the Viogen Tissue DNA Extraction Kit (cat. no: GG2001-50). Q-
PCR was carried out using the following primers including forward primer: $F$ 5'-AGG GAC AGA AGT CGA AGG GG-3' and reverse primer: R 5'-GCA GCC AAG CCG GAA ACA TC-3'. Amplification of a 164 bp fragment of RE gene was performed using SYBR green master mix (Thermo Scientific cat no: K0221) (10 $\mu \mathrm{l})$ mixed with $1.4 \mu \mathrm{l}$ of the template DNA to reach a final volume of $20 \mathrm{ml}$ containing $7 \mu \mathrm{l}$ distilled water and $0.8 \mu \mathrm{l}$ of each primer $(1 \mathrm{pmol} / \mu \mathrm{l})$. Afterward Q-PCR assays for each DNA sample was carried out in triplicate action. The number of tachyzoite in the samples was calculated as cycle threshold values (CT) based on a standard curve. The results of Q-PCR were presented as tachyzoite of T. gondii equivalents per mg of tissue [7].

\section{Statistical analysis}

The data were analyzed using SPSS software version 15. The comparison of data obtained with the drugs and control groups was analyzed by ANOVA and NewmanKeuls multiple comparison test. Differences were considered to be statistically significant between two groups when $P$ value was less than 0.05 .

\section{Results}

In the pre-treatment group, the highest parasitic load (copy number) of $T$. gondii was observed in the negative control group $(865,548$ parasites $/ \mathrm{ml})$. In contrast, in the case group, mice brain which were treated with KET ( $2 \mathrm{mg} / \mathrm{kg} /$ day), showed the lowest amount of parasite load (15,698 parasites/ml) (Table 1).

In the post-treatment groups, the lowest parasitic load $(13,299$ parasites $/ \mathrm{ml})$ was observed in the combinational therapy (KET $2 \mathrm{mg} / \mathrm{kg} /$ day and PYR) (Table 2). In the pretreatment and post-treatment groups, there was a significant difference between parasitic load in the treated and the untreated groups (negative control) $(P<0.001)$.

In comparison with the negative control group most of the infected mice in other groups displayed a

Table 1 Anti-Toxoplasma activity of KET and control groups in brain tissue in the pre-treatment groups

\begin{tabular}{llll}
\hline Drug/dose, mg & $C T($ mean \pm SD) & Parasite load & $P$ value \\
\hline KET & & & \\
2 & $28.26 \pm 0.77$ & 15,698 & $P<0.001$ \\
3 & $24.53 \pm 0.06$ & 72,898 & $P<0.001$ \\
KET and PYR & & & \\
$2+50$ & $23.37 \pm 1.15$ & 100,597 & $P<0.001$ \\
$3+50$ & $22.42 \pm 1.39$ & 196,591 & $P<0.001$ \\
PYR (positive control) & & & \\
50 & $25.28 \pm 0.82$ & 30,572 & $P<0.001$ \\
PBS (negative control) & $21.12 \pm 0.34$ & 865,548 & - \\
\hline
\end{tabular}


Table 2 Anti-Toxoplasma activity of KET and control groups in brain tissue in the post-treatment groups

\begin{tabular}{llll}
\hline Drug/dose, $\mathrm{mg}$ & $\mathrm{CT}(\mathrm{m}$ ean $\pm \mathrm{SD})$ & Parasite load & $P$ value \\
\hline KET & & & \\
2 & $25.40 \pm 0.51$ & 31,369 & $P<0.001$ \\
3 & $25.81 \pm 1.09$ & 21,043 & $P<0.001$ \\
KET and PYR & & & \\
$\quad 2+50$ & $27.26 \pm 0.52$ & 13,299 & $P<0.001$ \\
$\quad 3+50$ & $26.59 \pm 19.00$ & 16,630 & $P<0.001$ \\
PYR (positive control) & & & \\
$\quad 50$ & $25.54 \pm 0.54$ & 31,099 & $P<0.001$ \\
$\quad$ PBS (negative control) & $20.27 \pm 0.75$ & $1,325,000$ & - \\
\hline
\end{tabular}

considerable decrease in the parasite load or circulating parasite DNA levels, in their brains (Fig. 1 and Fig. 2).

\section{Discussion}

Standard treatment of toxoplasmosis is accompanied by significant side effects and low efficacies [6]. It was previously demonstrated that KET acts as a cell membrane stabilizer drug and thus can prevent tachyzoite of $T$. gondii from penetration into nucleated cells both in vitro and in vivo [15]. Our findings indicate that KET alone and in combination with PYR was remarkably effective against $T$. gondii.

Ryning and Remington showed that cytochalasin D inhibits the entry of T. gondii into peritoneal macrophages and bladder tumor cells. Microfilaments are most likely the common site of action for preventing the entrance of T. gondii into cells [18]. Also, Montazeri et al. reported a significant effect of propranolol against $T$. gondii infection in vivo. Propranolol as a beta-blocker, stabilizes cell

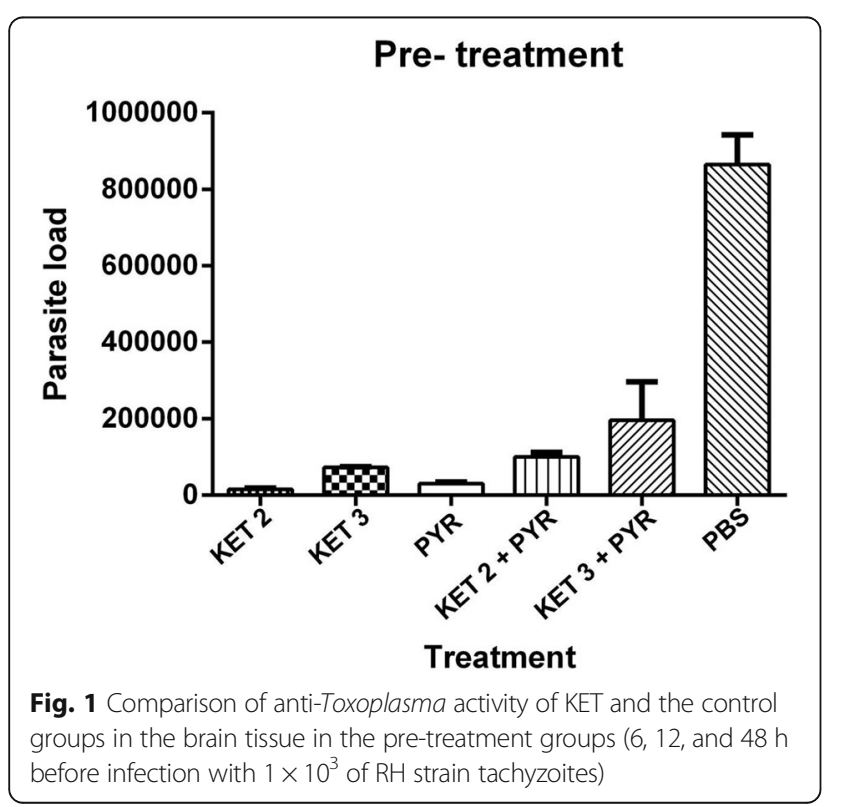

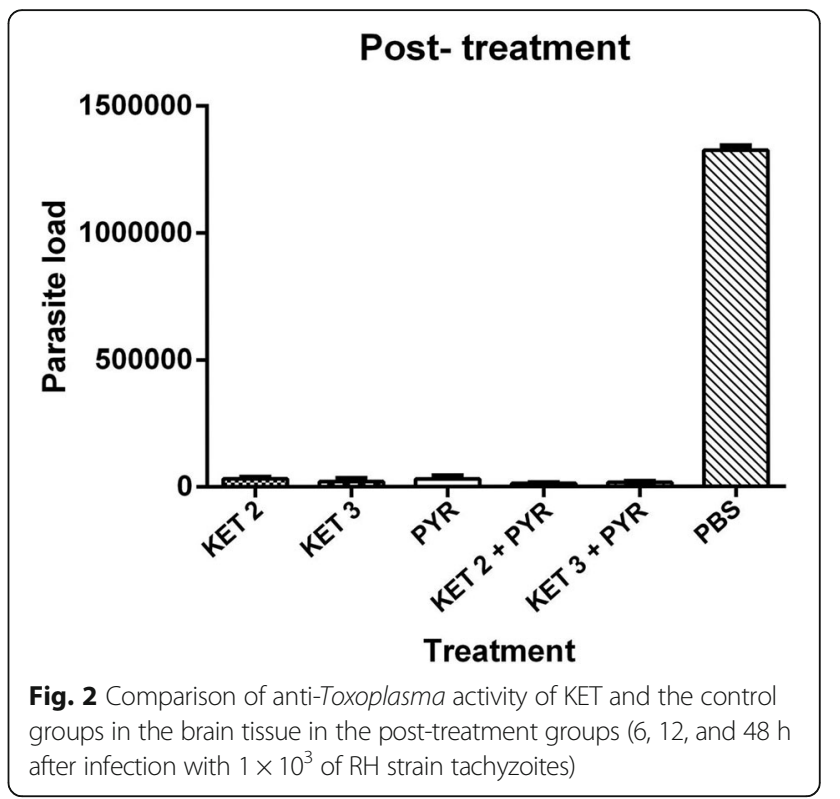

membrane and inhibits parasite entry into the host cells $[7,14]$. Similarly, our data demonstrated that KET individually and combined with PYR reduced the parasite load. Results indicated a remarkable effect of KET compared to a significant difference with the negative control group. However, the lowest parasitic load was observed in KET $(2 \mathrm{mg} / \mathrm{kg} /$ day $)$ in brain tissue in pre-treatment group compared to negative and positive controls. It is due to cell membrane stabilizing effect of KET.

In the post-treatment experiment, KET combined with PYR had the greatest effect in reducing the parasitic load in brain tissue. It was clearly demonstrated that KET (3 $\mathrm{mg} / \mathrm{kg} /$ day) combined with PYR significantly inhibited the intracellular proliferations of the tachyzoites of highly virulent RH strain of $T$. gondii.

Martins-Duarte et al. carried out a similar study in vivo and reported that fluconazole combined with sulfadiazine and PYR was highly effective against $T$. gondii [19]. Combination therapy is known as the most effective treatment for toxoplasmic encephalitis [20]. Monotherapy administration of PYR due to the danger of reactivation and relapse of toxoplasmosis is not recommended [21].

In addition, the combined administration of KET and PYR might decrease drug dosages and consequently reduce the drug's adverse effects. Similar effects were reported for spiramycin co-administered with metronidazole. These medications were highly efficient against the cystic form of $T$. gondii and significantly reduced the cyst load in the chronic toxoplasmosis in a mouse model [22].

Our previous studies demonstrated that the antiToxoplasma activity of propranolol combined with PYR in murine infection with the $\mathrm{RH}$ parasite strain in posttreatment group, significantly decreased parasitic load 
in brain tissue compared to the infected untreated control $(P<0.001)$. Therefore, the combined administration of KET and propranolol might lead to decrease in the drug dosages and consequently drug's side adverse effects [7, 14].

Eastman et al. indicated that KET can potently block the development of Plasmodium falciparum and P. yoelii oocysts (rodent parasite) in mosquitoes. Additionally, KET appeared to have some activities against relapse of P. cynomolgi infection in rhesus monkeys [23]. As there was not a significant difference in anti-Toxoplasma activity of drugs used in pre- and post-treatment groups, therefore, KET ( $2 \mathrm{mg} / \mathrm{kg} /$ day $)$ with low dose and fewer adverse effects has treatment efficiency equal to PYR on toxoplasmosis.

\section{Conclusions}

In conclusion, our results showed the prophylactic and therapeutic effects of KET in acute phases and that the efficiency increases in combinational therapy using both KET and PYR for the purpose of $T$. gondii inhibition in vivo. This could lead to introduction of a new drug for the treatment of toxoplasmosis, resulting in faster recovery from the disease. There is also an opportunity to decrease the dose of PYR and its related side effects using such combinations.

\section{Abbreviations}

ARCMUMS: Animal Research Center, Mazandaran University of Medical Sciences; CT: Cycle threshold values; IP: Intraperitoneal; KET 2: Ketotifen $2 \mathrm{mg} / \mathrm{kg} /$ day; KET 3: Ketotifen 3 mg/kg/day; KET: Ketotifen; MUMSEC: Mazandaran University of Medical Sciences Ethics Committee; PBS: Phosphate-buffered saline; PYR: Pyrimethamine; Q-PCR: QuantitativePCR; RE: Repeat element; T. gondii: Toxoplasma gondii

\section{Acknowledgements}

This study was prepared from K. Rezaii MSc thesis and supported by grant (no. 92-473) from Deputy of Research, Mazandaran University of Medical Sciences, Sari, Iran. The sponsor or funding organization had no role in the design or conduct of this research.

\section{Funding}

This work was supported by the Deputy of Research, Mazandaran University of Medical Sciences, Sari, Iran.

\section{Availability of data and materials}

Not applicable.

\section{Authors' contributions}

$A D, M S, S S$, and MAE conceived of the study. MM, KR, EA, and ASP supervised the laboratory examinations. MM wrote the manuscript. MTR and SM helped to draft the manuscript. All authors read and approved the final manuscript.

\section{Ethics approval}

This survey was performed according to animal ethics institute guidelines. The animal protocols were approved by Animal Research Center, Mazandaran University of Medical Sciences (ARCMUMS). Ethical approval was obtained from the Mazandaran University of Medical Sciences Ethics Committee (MUMSEC) (permit number 473).

\section{Consent for publication}

Not applicable.

\section{Competing interests}

The authors declare that they have no competing interests.

\section{Publisher's Note}

Springer Nature remains neutral with regard to jurisdictional claims in published maps and institutional affiliations.

\section{Author details}

${ }^{1}$ Toxoplasmosis Research Center, Mazandaran University of Medical Sciences, Sari, Iran. ${ }^{2}$ Student Research Committee, Mazandaran University of Medical Sciences, Sari, Iran. ${ }^{3}$ Pharmaceutical Sciences Research Center, School of Pharmacy, Mazandaran University of Medical Sciences, Sari, Iran. ${ }^{4}$ Department of Parasitology and Mycology, Sari Medical School, Mazandaran University of Medical Sciences, Sari, Iran. ${ }^{5}$ Infectious and Tropical Diseases Research Center, Tabriz University of Medical Sciences, Tabriz, Iran. ${ }^{6}$ School of Medicine,

Shahroud University of Medical Sciences, Shahroud, Iran. ${ }^{7}$ Razi Drug Research Center, Iran University of Medical Sciences, Tehran, Iran.

Received: 22 September 2017 Accepted: 12 November 2017

Published online: 21 November 2017

\section{References}

1. Tenter AM. Toxoplasma gondii in animals used for human consumption. Mem Inst Oswaldo Cruz. 2009;104(2):364-9.

2. Scallan E, Hoekstra RM, Angulo FJ, Tauxe RV, Widdowson M-A, Roy SL, et al. Foodborne illness acquired in the United States-major pathogens. Emerg Infect Dis. 2011;17(1):7-15.

3. Ahmadpour E, Daryani A, Sharif M, Sarvi S, Aarabi M, Mizani A, et al. Toxoplasmosis in immunocompromised patients in Iran: a systematic review and meta-analysis. J Infect Dev Ctries. 2014;8(12):1503-10.

4. Carlier Y, Truyens C, Deloron P, Peyron F. Congenital parasitic infections: a review. Acta Trop. 2012;121(2):55-70.

5. Moncada PA, Montoya JG. Toxoplasmosis in the fetus and newborn: an update on prevalence, diagnosis and treatment. Expert Rev Anti-Infect Ther. 2012;10(7):815-28.

6. Montazeri M, Sharif M, Sarvi S, Mehrzadi S, Ahmadpour E, Daryani A. A systematic review of in vitro and in vivo activities of anti-Toxoplasma drugs and compounds (2006-2016). Front Microbiol. 2017;8:25.

7. Montazeri M, Ebrahimzadeh MA, Ahmadpour E, Sharif M, Sarvi S, Daryani A. Evaluation of propranolol effect on experimental acute and chronic toxoplasmosis using quantitative PCR. Antimicrob Agents Chemother. 2016; 60(12):7128-33

8. Alomar ML, Rasse-Suriani FA, Ganuza A, Cóceres VM, Cabrerizo FM, Angel SO. In vitro evaluation of $\beta$-carboline alkaloids as potential anti-Toxoplasma agents. BMC Res Notes. 2013;6(1):193.

9. Sibley DL, Charron A, Hakansson S, Mordue D. Invasion and intracellular survival by Toxoplasma. Madame Curie Biosci Database. 2013:2000-3.

10. Walker DM, Oghumu S, Gupta G, McGwire BS, Drew ME, Satoskar AR. Mechanisms of cellular invasion by intracellular parasites. Cell Mol Life Sci. 2014;71(7):1245-63.

11. Grant SM, Goa KL, Fitton A, Sorkin EM. Ketotifen. A review of its pharmacodynamic and pharmacokinetic properties, and therapeutic use in asthma and allergic disorders. Drugs. 1990;40(3):412-48.

12. Nabe M, Miyagawa H, Agrawal DK, Sugiyama H, Townley RG. The effect of ketotifen on eosinophils as measured at LTC4 release and by chemotaxis. Allergy Proc. 1991;12(4):267-71.

13. Daryani A, Ebrahimzadeh M-A, Sharif M, Rezaei F, Ahmadpour E, Sarvi S, et al. The inhibitory effect of ketotifen on entrance of Toxoplasma gondii tachyzoites into macrophages of mouse. J Maz Univ Med Sci. 2014;23(110):75-80.

14. Montazeri M, Daryani A, Ebrahimzadeh M, Ahmadpour E, Sharif M, Sarvi S. Effect of propranolol alone and in combination with pyrimethamine on acute murine toxoplasmosis. Jundishapur J Microbiol. 2015;8(9):e22572.

15. Rezaei F, Ebrahimzadeh MA, Daryani A, Sharif M, Ahmadpour E, Sarvi S. The inhibitory effect of cromolyn sodium and ketotifen on Toxoplasma gondii entrance into host cells in vitro and in vivo. J Parasit Dis. 2016;40(3):1001-5.

16. Daryani A, Hosseini AZ, Dalimi A. Immune responses against excreted/ secreted antigens of Toxoplasma gondii tachyzoites in the murine model. Vet Parasitol. 2003;113(2):123-34.

17. Akins CK, Panicker SE, Cunningham CL. Laboratory animals in research and teaching: ethics, care, and methods. Am Psychol Assoc. 2005:274. 
18. Ryning FW, Remington JS. Effect of cytochalasin D on Toxoplasma gondii cell entry. Infect Immun. 1978;20(3):739-43.

19. Martins-Duarte ÉS, de Souza W, Vommaro RC. Toxoplasma gondii: the effect of fluconazole combined with sulfadiazine and pyrimethamine against acute toxoplasmosis in murine model. Exp Parasitol. 2013;133(3):294-9.

20. Rajapakse S, Chrishan Shivanthan M, Samaranayake N, Rodrigo C, Deepika FS. Antibiotics for human toxoplasmosis: a systematic review of randomized trials. Pathog Glob Health. 2013;107(4):162-9.

21. Foppa CU, Bini T, Gregis G, Lazzarin A, Esposito R, Moroni M. A retrospective study of primary and maintenance therapy of toxoplasmic encephalitis with oral clindamycin and pyrimethamine. Eur J Clin Microbiol Infect Dis. 1991;10(3):187-9.

22. Chew WK, Segarra I, Ambu S, Mak JW. Significant reduction of brain cysts caused by Toxoplasma gondii after treatment with spiramycin coadministered with metronidazole in a mouse model of chronic toxoplasmosis. Antimicrob Agents Chemother. 2012;56(4):1762-8.

23. Eastman RT, Pattaradilokrat S, Raj DK, Dixit S, Deng B, Miura K, et al. A class of tricyclic compounds blocking malaria parasite oocyst development and transmission. Antimicrob Agents Chemother. 2013;57(1):425-35

\section{Submit your next manuscript to BioMed Central} and we will help you at every step:

- We accept pre-submission inquiries

- Our selector tool helps you to find the most relevant journal

- We provide round the clock customer support

- Convenient online submission

- Thorough peer review

- Inclusion in PubMed and all major indexing services

- Maximum visibility for your research

Submit your manuscript at www.biomedcentral.com/submit 